\title{
INTERLOCUÇÕES ENTRE O PLANTÃO PSICOLÓGICO E O PSICODIAGNÓSTICO COLABORATIVO
}

\author{
DIALOGUE BETWEEN PSYCHOLOGICAL DUTY \\ AND COLLABORATIVE ASSESSMENT
}

\author{
Gohara Yvette YEHIA ${ }^{1}$
}

\begin{abstract}
RESUMO
A busca de novas formas de atendimento psicológico em instituições, que se preocupam com os serviços oferecidos à população que as procura, resultou no desenvolvimento de práticas como o plantão psicológico, serviço cada vez mais oferecido em instituições para acolher o cliente, e o psicodiagnóstico colaborativo que se propõe a uma intervenção que, tradicionalmente, é deixada para momentos posteriores, quando da realização da psicoterapia, caso indicada. A partir de depoimentos de alunos de um curso de aperfeiçoamento em psicodiagnóstico colaborativo, oferecido no Serviço de Aconselhamento Psicológico da USP, onde habitualmente são desenvolvidas as atividades referentes ao plantão psicológico, o presente trabalho tem como objetivo focalizar as possiveis interlocuções entre estas práticas, assim como sua contribuição para o acolhimento do cliente e a formação do aluno.
\end{abstract}

Palavras-chave: Psicodiagnóstico colaborativo; plantão psicológico, práticas psicológicas em instituição.

\begin{abstract}
The search for new ways of psychological care in institutions worried about the services offered to people who come for it, led to the development of practices as psychological duty, a service that has been more and more offered to receive the client, and the collaborative assessment that aims an intervention, traditionally postponed when psychotherapy begins, when necessary. Based on statements of students from an improvement course, on collaborative assessment, at the Serviço de Aconselhamento Psicoló-
\end{abstract}

(1) Doutora em Psicologia. Endereço para correspondência: E-mail: gohara1@terra.com.br 
gico - USP, where usually are developed activities related to psychological duty, the present research aims to focus the possible dialogue between these practices, and their contribution to the reception of the client and the training of the students.

Key words: Collaborative assessment; psychological duty; psychological care in institutions.

A partir de um convite do Laboratório de Estudos em Fenomenologia do Serviço de Aconselhamento Psicológico (SAP) da USP, ministrei no primeiro semestre de 1999 uma disciplina: Psicodiagnóstico em questão: diferentes práticas e pesquisas, no programa de Pós-graduação do Departamento de Psicologia da Aprendizagem, do Desenvolvimento e da Personalidade do Instituto de Psicologia da USP, assim como um curso de aperfeiçoamento: Psicodiagnóstico fenomenológico-existencial: um processo colaborativo.

Para o curso de aperfeiçoamento, os alunos usaram as dependências do SAP que também fez a divulgação da oferta de atendimento em psicodiagnóstico, o que permitiu a inclusão de uma população não contemplada por este setor até o momento: crianças e seus pais.

Assim sendo, os clientes que procuravam atendimento infantil foram inicialmente atendidos por estagiários do curso de Psicologia que atuavam no Plantão Psicológico e os encaminhavam aos alunos do curso de aperfeiçoamento em psicodiagnóstico colaborativo. Alguns destes alunos haviam concluído o curso de Psicologia na USP e passado pela experiência do Plantão Psicológico.

Deste modo, nas aulas teóricas e nas supervisões foram sendo trazidas à luz e discutidas convergências e divergências entre o Plantão Psicológico e o Diagnóstico Colaborativo, o que nos levou a buscar uma primeira formalização da possível interlocução entre estas duas modalidades de atendimento.

\section{Um pouco do que está escrito a respeito de - Plantão Psicológico}

Entrei em contato pela primeira vez com a questão do Plantão Psicológico no texto de Ancona-Lopez, S. (1996) que discute as entrevistas de triagem propondo-se a torná-las um momento significativo em si, para o cliente, independentemente do eventual encaminhamento para outro tipo de atendimento. Esta autora menciona um texto de 1987, de Mahfoud, que se refere ao Plantão Psicológico como um desafio, propondo que seja um "momento significativo da pessoa ante sua problemática" (1987, p. 82).

Mais recentemente, no livro organizado por Morato, em 1999, há varias referências a Plantão Psicológico, considerado como possibilidade de um atendimento emergencial ou o início de um processo que se estenderá por uma ou mais sessões, utilizado por quem o procure: adulto, família, adolescente, em qualquer instituição (clínica, judiciária, escolar, hospitalar) onde haja profissionais disponíveis para um atendimento psicológico.

Nas palavras de Schmidt (1999), o Plantão Psicológico "está estruturado para que o cliente seja acolhido por um espaço de escuta qualificada, no momento mesmo em que procura auxílio. Este acolhimento exige a priorização da entrevista psicológica (...) Esta entrevista não é pensada como triagem (...) mas como espaço propício à elaboração da experiência do cliente no que diz respeito ao sofrimento psíquico que ele porta e às possibilidades ou vislumbres de ajuda que ele concebe. Assim, a entrevista de Plantão visa facilitar que o cliente clarifique a natureza de seu sofrimento e de sua demanda por ajuda."

(2) Grifo meu. 
Entende-se que o que define o plantão não é a queixa trazida pelo cliente mas o modo de lidar com a mesma, compreendida como "um sintoma de uma demanda cujo esforço de compreensão é feito na medida em que interesse ao cliente" (Morato, 1999). De fato, trata-se, em vez de focalizar o sintoma do cliente, de acolher sua experiência, procurando tornar este encontro significativo.

\section{Psicodiagnóstico Interventivo/colaborativo}

Embora a prática do psicodiagnóstico venha sendo discutida há vários anos, ela ainda é concebida em sua forma tradicional, ou seja, como um atendimento que resulta em uma avaliação que poderá levar a uma indicação terapêutica mais bem fundamentada.

Esse modo de realizar o psicodiagnóstico faz com que haja uma separação nítida entre a etapa do diagnóstico (em que a proposta é a realização de uma investigação) e a devolução do conhecimento e compreensão adquiridos a partir da investigação. Este procedimento dificulta a retomada de atitudes do paciente que possam contribuir para uma melhor integração do material devolvido, já que o momento em que se dá a devolução se refere a acontecimentos passados.

No psicodiagnóstico colaborativo, a proposta é a explicitação da experiência do cliente, à medida que a ela se refere ou que vai sendo percebida na relação estabelecida com o psicólogo. "Quando se trata do psicodiagnóstico infantil, o trabalho com os pais visa explorar o significado da queixa trazida, dos sintomas apresentados pela criança, a compreensão que eles têm de sua própria situação e de sua relação com o filho" (Yehia, 1998, p. 118). Mesmo quando o paciente designado é a criança, a participação dos pais no atendimento é extremamente importante sendo que, enquanto o atendimento psicológico proposto não tiver sentido para eles, que se limitam a seguir a indicação de outro profissional, submetendo-se à mesma, e sem expectativa em relação ao mesmo, é muito difícil chegar a uma compreensão conjunta do que possa estar acontecendo com a criança no contexto pessoal, familiar e social.

Nesta proposta, a situação de psicodiagnóstico torna-se "uma situação de cooperação ${ }^{3}$ em que a capacidade de ambas as partes de observarem, aprenderem, compreenderem constitui a base indispensável para o trabalho" (Yehia, 1999, p. 120). O psicólogo compartilha com os pais sua própria experiência com eles e com a criança, sugere alternativas de ação, dá sugestões a respeito do que considera capaz de promover um desenvolvimento mais harmonioso, propondo um redirecionamento dos pais a partir da compreensão da criança e da dinâmica familiar, com o objetivo de facilitar o relacionamento, propiciar novas formas de interação e abrir novas perspectivas experienciais.

Entretanto para que se possa estabelecer uma situação de cooperação entre psicólogo e cliente é necessário que haja uma demanda do último. O que entendemos por demanda? Temos um cliente que vem procurar um atendimento, muitas vezes após ter esgotado os recursos disponíveis (vai passar, a criança vai crescer, mudança de atitude em relação ao filho, etc.); finalmente, surge o encaminhamento por parte de um terceiro ou a procura espontânea pelo atendimento. Quando estamos no primeiro caso, é importante verificar como o cliente se posiciona diante deste encaminhamento, pois no psicodiagnóstico colaborativo, se a demanda for de um terceiro e esta questão não for trabalhada com os responsáveis, o trabalho fica praticamente inviabilizado. Dever-se-ia, então, procurar saber com este terceiro qual é a sua demanda e talvez trabalhar com ele. No segundo caso, quando há procura espontânea pelo atendimento psicológico, ainda é preciso saber, no caso de um psicodiagnóstico infantil, se há demanda dos pais ou se eles apenas estão querendo que o psicólogo faça o que eles não estão conseguindo fazer: resolver uma situação difícil.

(3) Nesta apresentação escolhi me referir ao psicodiagnóstico como processo colaborativo, embora as publicações a respeito da forma proposta para realizar este trabalho se refiram ao psicodiagnóstico interventivo. 
Assim, no início do psicodiagnóstico colaborativo, é necessário desenvolver um trabalho com os pais no sentido de ajudá-los a se apropriarem da demanda, propondo-se a problematizar suas relações com o filho, com eles mesmos, com os outros. A explicitação dos pais em relação à expectativa que eles têm de um atendimento psicológico também deve ser focalizada, já que partimos do pressuposto que o psicólogo não trabalha sozinho. Mesmo que ao final do processo se chegue à conclusão de que é a criança que necessita de tratamento, a colaboração dos pais é imprescindível uma vez que a criança depende deles e, em geral, seus sintomas são modos de ela expressar "coisas que não vão bem", não apenas com ela mesma, mas também no seio da família.

Aqui já antevejo possibilidades de interlocução entre o plantão psicológico e o diagnóstico interventivo, pelo menos no que se refere a este início do relacionamento entre o psicólogo e o cliente que vem buscar atendimento.

Para que os pais possam apropriar-se de sua demanda, a ajuda do psicólogo é importante no sentido de clarear expectativas, delimitar papéis, e envolver os participantes numa proposta de trabalho.

Se pensarmos em termos da ansiedade do cliente em relação aos problemas que vem enfrentando, muitas vezes o confronto com os pressupostos que o trazem e que orientam sua compreensão de uma situação pode ajudá-lo a lidar melhor com a mesma, re-orientando sua demanda.

\section{Abordagem teórica}

Tanto o Plantão Psicológico como o Psicodiagnóstico colaborativo partem de uma perspectiva fenomenológico-existencial, o que leva a uma semelhança no que diz respeito à atitude diante do cliente e à concepção de saúde e doença. Ambas as práticas propõem-se a estimular os aspectos saudáveis presentes na experiência do sujeito, e a não classificar ou rotular.
A partir da posição humanista, a atitude do psicólogo é de acolhimento ao cliente de uma forma empática, buscando compreendê-lo, respeitando seus limites e procurando ampliar suas possibilidades.

A fenomenologia nos oferece um método de pesquisa para trabalhar com o fenômeno, entendendo-o como aquilo que se mostra, desvelando aquilo que faz com que ele me pareça desta ou daquela maneira, ou seja, explicitando os pressupostos que orientam a compreensão daquilo que está sendo focalizado.

O existencialismo nos traz a compreensão do homem como ser-no-mundo (sendo ser e mundo instâncias inseparáveis e que são um neste indivíduo) com-os-outros. Desta maneira, não estaremos procurando os aspectos internos do cliente, que fazem com que tal ou qual coisa se manifeste desta ou daquela maneira, mas trabalharemos sempre no entre (ser e mundo com os outros), no modo de como as coisas aparecem, no significado que elas têm para o psicólogo e para o cliente, considerando que cada um de nós toma, o tempo todo, decisões pessoais, dando sentido à sua própria existência (mesmo que não se dê conta disto). Mundo, neste contexto, é a possibilidade de algo nos parecer como sendo isto ou aquilo, sistema de remissões possíveis, rede de significações em que cada coisa é o que é, remetendo a outras. Assim, as interpretações são desenvolvidas via interpretações-significados, vistos a partir de determinada perspectiva que trata de esclarecer e compartilhar já que a realidade humana é sempre situada no mundo.

Para o psicólogo que se propõe a desenvolver um psicodiagnóstico colaborativo com crianças e seus pais, vários conhecimentos são imprescindíveis, devendo muitas vezes ser resgatados:

- noções de psicologia do desenvolvimento, já que é importante situar a queixa em relação a uma fase do desenvolvimento e a um momento de vida pelo qual a família passa. Por exemplo, uma criança que apresenta enurese noturna faz com que o psicólogo se coloque uma série de 
perguntas: como se deu o ensino do controle esfincteriano, o que está acontecendo no momento atual, a criança já havia adquirido o controle e o perdeu, ou nunca o adquiriu? Cada uma destas perguntas é orientada por conhecimentos provindos de abordagens teóricas que focalizam desenvolvimento individual, inserção de um indivíduo na família, dinâmica familiar, crescimento e regressão;

- conhecimentos oriundos das teorias a respeito de família, dinâmica familiar, bode expiatório, relacionamento diádico, triádico, etc;

- conhecimentos de psicologia escolar também são resgatados, uma vez que esta criança freqüenta uma determinada escola que foi escolhida por seus pais e tem uma determinada filosofia. Será que há coincidência entre a filosofia da escola e dos pais? Será que a escola atende às necessidades desta criança? Como é o tamanho da classe, como é a atitude da professora? De uma maneira geral, uma criança que não tenha dificuldade adapta-se a qualquer tipo de escola e, portanto, estas perguntas não se colocam. Mas quando há dificuldades da criança na escola, antes de pensarmos apenas que a questão se coloca na criança, é importante pesquisarmos a relação entre a criança, a família e a escola.

Resumindo, examinam-se aspectos biológicos, biográficos, ambientais, em termos de suas contribuições à situação atual da criança e de sua família.

No psicodiagnóstico colaborativo o psicólogo utiliza-se dos instrumentos psicológicos disponíveis, sejam eles provindos da psicometria, sejam testes projetivos, seja observação lúdica, etc.

Assim, um conhecimento destes instrumentos é muito importante, já que ignorá-los seria desconsiderar várias possibilidades oferecidas ao psicólogo e desenvolvidas com a finalidade de melhor conhecer o cliente. Entendemos que eles funcionam como organizadores de uma experiência e, quando não usados como anteparos entre o psicólogo e o cliente, podem ser dinamizadores de várias possibilidades relacionais e interventivas. Permitem que psicólogo e cliente observem a pessoa realizando uma atividade. Situações semelhantes, ocorridas no passado, tornam-se disponíveis para o cliente, podendo ser retomadas e revistas, abrindo-se novas perspectivas e ampliando-se possibilidades.

\section{A investigação preliminar}

As questões colocadas a partir das discussões a respeito de psicodiagnóstico em geral e de psicodiagnóstico interventivo na abordagem fenomenológico-existencial em particular surpreenderam os alunos que, em sua maioria, partiam da concepção clássica do psicodiagnóstico. Mesmo para aqueles que haviam entrado em contato com textos a respeito do psicodiagnóstico como processo de intervenção, a abordagem fenomenológico-existencial não havia sido significativa.

De fato, de uma maneira geral, a abordagem fenomenológica ainda representa uma ruptura em relação a posições tradicionais relacionadas à cientificidade, ao conhecimento, à verdade, etc. De fato, a noção de relação intencional, de ser-no-mundo como unidade indivisível, ainda acarreta certo estranhamento, já que a formação científica, até hoje, ainda mantém a separação sujeito $x$ objeto, sujeito $x$ ambiente, teorias verdadeiras ou falsas.

O humanismo enfatiza a questão do cuidado e a questão da relação com o outro, que em situações terapêuticas são mais focalizadas. $O$ psicodiagnóstico clássico, por outro lado, levanta a questão de se saber qual é a "verdade" em relação a este sujeito, na medida em que tradicionalmente seu objetivo é compreender o que está acontecendo com ele, para chegar a uma indicação terapêutica melhor fundamentada e a um prognóstico.

Assim, tendo em vista que se discutia a questão da queixa, o esclarecimento da demanda e, principalmente, a co-constituição da compreensão daquilo que está acontecendo, a revisão da posição do psicólogo, a atividade do cliente, é que os alunos puderam começar a considerar o psicodiagnóstico sob uma nova perspectiva. 
- “Ler o psicodiagnóstico desta forma é trazer o outro para a posição da gente. O processo perde o caráter tradicional, onde a pessoa é receptor passivo da ação de alguém."

- "O Psicodiagnóstico trabalha muitas coisas e não simplesmente rotula, o Plantão também inicia um 'tratamento' que pode ser encerrado ou servir como clareador para um encaminhamento."

- "É preciso uma resignificação do sentido do psicodiagnóstico, considerando-o uma prática de essência no cuidado com a pessoa do cliente."

Os alunos começaram a se dar conta da importância da relação estabelecida entre psicólogo e cliente, da co-responsabilidade no desenvolvimento do trabalho, da mudança de posição do psicólogo, não mais detentor do saber, mas representante de um outro ponto de vista a ser compartilhado com o cliente.

- "No psicodiagnóstico fenomenológico-existencial, o profissional também trabalha a partir do básico: as relações humanas."

- "O psicodiagnóstico fenomenológico-existencial e o plantão psicológico tratam a relação cliente/psicólogo de um forma muito semelhante."

- "O enfoque adotado pelo psicodiagnóstico é muito próximo do plantão."

Penso que, pelo fato de o plantão psicológico ter nascido e se desenvolvido no SAP que, tradicionalmente, privilegia a abordagem humanista, a terapia centrada no cliente (avessa ao psicodiagnóstico em sua acepção tradicional) é que, a partir do contato com o psicodiagnóstico colaborativo, alguns alunos perceberam que o psicodiagnóstico poderia contribuir com a atividade de plantão:

- "sinto que o objetivo principal do plantão é atender a necessidade emergencial que a pessoa tenha, seja ela qual for, quando procura um plantão. Esclarecer, ouvir, orientar, re-orientar a pessoa na sua solicitação é já um psicodiagnóstico à medida que este olhar àquilo que a pessoa traz demanda uma especificidade clínica e uma certa organização e direcionamento que a pessoa não está encontrando por si só."
- "O psicodiagnóstico poderia contribuir com o plantão na questão do esclarecimento da demanda daquele que procura o serviço."

A questão do esclarecimento da demanda é sublinhada, considerando que o trabalho com psicodiagnóstico trouxe a possibilidade de uma "organização mais objetiva" para quem faz plantão. De fato, quando falamos em "esclarecer demanda", pensamos no que acontece quando a atitude natural, a partir da qual lidamos com o mundo sem nos perguntarmos a respeito do significado de cada coisa, não é mais possível. Quando o mundo se torna obstrutivo (quando a totalidade estruturada de significados e de intenções inter-relacionadas perde o sentido), quando surge a pergunta, é que é necessário "tematizar" e debruçar-se sobre o fenômeno tematizado.

Entendemos por isto que, como dito anteriormente, é necessário que o psicólogo, junto com os pais, possa "explorar o significado da queixa trazida, dos sintomas apresentados pela criança, a compreensão que eles têm de sua situação e de sua relação com o filho. (...) numa situação de cooperação em que a capacidade de ambas as partes observarem, apreenderem, compreenderem constitui a base indispensável para o trabalho. Tanto os pais como o psicólogo observam a si mesmos e ao outro, tanto os pais como o psicólogo procuram compreender o que está sendo vivenciado, sendo que a compreensão dos pais e a do psicólogo são equivalentes e compartilhadas". (Yehia, 1998, pp. 118-120).

Embora fale de pais, pois nossa prática se dá principalmente com crianças cujos pais procuram um serviço psicológico, penso que é possível trabalhar da mesma maneira com um adulto ou um adolescente que estejam procurando atendimento para si mesmos.

Nas palavras de uma aluna:

- "Acredito que o psicodiagnóstico poderia ajudar a 'objetivar' questões surgidas no plantão, principalmente no que se refere ao esclarecimento da demanda daquele que procura o serviço." 
- “O plantão atende toda a necessidade emergencial (atende tudo) que a pessoa tenha, seja ela qual for. Se incorporar o psicodiagnóstico, teria a possibilidade de organização, de direcionamento daquilo que é trazido."

No que diz respeito aos recursos utilizados pelo psicólogo que realiza o psicodiagnóstico interventivo, estes também são vistos como possíveis auxiliares para a compreensão do cliente que procura o plantão.

- “O plantonista 'iluminado' pela aprendizagem da proposta do psicodiagnóstico fenomenológico-existencial pode ampliar a maneira de receber o cliente no plantão. O fazer do psicólogo em psicodiagnóstico fenomenológico-existencial abre-se para o uso de recursos como a anamnese, o material lúdico, os testes, a visita domiciliar, a escolar, de uma maneira que isto ajuda a iluminar o fenômeno".

De fato, inicialmente, houve uma certa resistência ao uso dos testes psicológicos, principalmente os de nível intelectual, já que estes, por definição, dão um resultado objetivo (QI), não sendo geralmente pensados como organizadores da experiência da criança naquele momento e reprodução de situações de seu cotidiano (escola, casa), revelando os modos e a eficácia da criança ao lidar com elas.

O contato com o psicodiagnóstico colaborativo suscitou alguns comentários, dentre os quais o de que tal atendimento seria um "luxo". Aqui, retomo algo em relação a que venho insistindo nos últimos 20 anos de prática em instituição, ou seja, que "o cliente, desde o primeiro momento em que procura uma clínica-escola tem direito a um atendimento psicológico digno deste nome" (Yehia, 1983).

O sentido deste trabalho foi captado por uma das alunas:

- "é preciso uma resignificação do sentido do psicodiagnóstico, considerando-o uma prática não de 'luxo' mas de essência no cuidado com a pessoa do cliente".

\section{CONCLUSÃO}

A investigação preliminar permite dizer que, profissionais que têm contato com a prática do plantão psicológico e que entram em contato com o psicodiagnóstico colaborativo, na abordagem fenomenológico-existencial, dão-se conta da oposição à postura tradicional em relação a conhecimento e verdade já que o enfoque teórico está orientado na mesma direção (fenomenológico-existencial), valorizando a relação com o outro, focalizando a compreensão do que esteja acontecendo consigo próprio e com o outro.

Sabemos que o psicodiagnóstico fenomenológico-existencial é proposto como uma prática interventiva. Constituiu-se a partir da insatisfação de profissionais que se davam conta da ineficiência dos procedimentos tradicionais para o atendimento aos clientes, propondo-se a tornálos mais participantes, estando o próprio psicólogo mais engajado e ativo na relação estabelecida com os clientes.

Neste sentido, podemos vislumbrar uma posição ético-política, na medida em que a propostaé devolver ao cliente suas possibilidades de ser, ampliando suas possibilidades e horizontes, estimulando-o a assumir uma posição de cidadania. Também, por parte dos profissionais, há uma apropriação de um fazer clínico, desde o início do atendimento ao cliente (o fazer clínico, como já foi dito, era adiado para depois do psicodiagnóstico). Por fazer clínico entendemos, retomando a etimologia da palavra clínico, o inclinar-se para o sofrente, desde o primeiro contato com este.

Por outro lado, o psicodiagnóstico, compreendido como conhecer (gnose) através de (dia), pode se dar a partir do encontro entre psicólogo e cliente, propiciando, na medida do possível, a abertura para novas possibilidades de compreensão, a partir do estranhamento, saindo do impessoal e apropriando-nos da experiência vivida. Deste modo, o psicólogo se mantém em contato com a experiência do cliente, "contato vivido, afetivo e intelectual". (Figueiredo, 2000, p. 17). 
Em texto de 1998, eu dizia que o processo psicodiagnóstico é referido por pais que por ele passaram como "uma oportunidade para prestar atenção, perceber e pensar sobre o que está acontecendo". Na medida em que o cliente tem a oportunidade de "rever sua maneira de se relacionar com o filho, perceber novos sentidos possíveis para as situações de interação com ele, reformulando sua forma de exercer seu papel e, às vezes, seu desenvolvimento enquanto pessoa", o psicodiagnóstico colaborativo apresenta aspectos terapêuticos.

De fato, na medida em que o psicólogo trabalha a partir da ruptura, que gera a pergunta (Yehia, 1988 p. 117), o cotidiano é desnaturalizado e com a ajuda do psicólogo (seus questionamentos, intervenções, orientações), os pais vão desenvolvendo sua capacidade de pensar, de se colocar diante das questões que aparecem e de tomar decisões.

No plantão psicológico, cujo objetivo é o atendimento emergencial à demanda, temos uma proposta muito semelhante, embora esta prática tenha se desenvolvido a partir de um outro contexto, o de aconselhamento psicológico, "solo para as tensões da existência do homem em situação de vida no mundo com os outros, ou seja das relações interpessoais" (Morato, 1999, p. 83), nem sempre visto como atividade clínica.

De fato, ambas as práticas nasceram e se desenvolveram em contextos institucionais, fruto da insatisfação de profissionais com o atendimento oferecido aos clientes e que ousaram debruçar-se sobre a experiência e criar! Ambas as práticas propõem-se dar acolhimento ao cliente enquanto sofrente, trabalhando a partir de uma compreensão mais ética do que técnica (a respeito deste tema vide Figueiredo, 2000), permitindo o aparecimento de possibilidades existenciais encobertas pela calcificação decorrente do predomínio do cotidiano.

\section{REFERÊNCIAS BIBLIOGRÁFICAS}

ANCONA-LOPEZ, S. A.. Porta de Entrada - Da entrevista de triagem à consulta psicológica, Tese de Doutoramento, PUCSP, 1996

FIGUEIREDO, L.C. \&Coelho Junior, Ética e Técnica em Psicanálise, Escuta, São Paulo, 2000.

MAHFOUD, M., A Vivência de um Desafio: plantão psicológico. In: Rozemberg, R.L. (org), Aconselhamento Psicológico Centrado na Pessoa. São Paulo: EPU, 1987.

MORATO, H.T.P. (org), Aconselhamento Psicológico Centrado na Pessoa - Novos Desafios, São Paulo, Casa do Psicólogo, 1999.

SCHMIDT, M.L.S., Aconselhamento Psicoló-gico e Instituição: Algumas Considerações sobre o Serviço de Aconselhamento Psicológico do IPUSP, in Morato, H.T.P. (org.) Aconselhamento Psicológico Centrado na Pessoa-Novos Desafios, São Paulo, Casa do Psicólogo, 1999.

YEHIA, G.Y., Reformulação do papel do psicólogo no psicodiagnóstico fenomenológico-existencial e sua repercussão sobre os pais, in Ancona-Lopes, M. (org) Psicodiagnóstico: Processo de Intervenção, São Paulo, Cortez, 1998(2a ed).

YEHIA, G.Y., Proposta de uma técnica alternativa de supervisão de estágio para a formação de psicólogos, Dissertação de Mestrado, Psicologia Clínica, PUC-SP, 1983.

Recebido para publicação em 23 de abril de 2003 e aceito em 7 de novembro de 2003. 